\title{
Active and Reactive Power Control based on an Inner Predictive Voltage Control Loop for AC generation systems with Direct Matrix Converter
}

\author{
S. Toledo and M. Rivera \\ Dept. of Electrical Engineering \\ Univerisdad de Talca \\ Curicó, Chile \\ \{stoledo,mrivera\}@utalca.cl
}

\author{
P. Wheeler \\ Dept. of Electrical and Electronic Engineering \\ University of Nottingham \\ Nottingham, UK \\ pat.wheeler@nottingham.ac.uk
}

\author{
T. Dragicevic \\ Dept. of Energy Technology \\ Aalborg University \\ Aalborg, Denmark \\ tdr@et.aau.dk
}

\author{
D. Caballero, R. Gregor, E. Maqueda and F. Gavilán \\ Engineering Faculty \\ Universidad Nacional de Asunción \\ Luque, Paraguay \\ \{rgregor,emaqueda,dcaballero,fgavilan\}@ing.una.py
}

\begin{abstract}
In order to satisfied the growing electrical energy demand around the world, renewable energy generation systems under distributed generation frame emerges as a plausible solution. In this context wind and micro-hydro generation systems consist of renewable $\mathrm{AC}$ sources that need efficient and totally controlled power conversion stages. In this work a novel active and reactive power control strategy based on two cascade control loops using a combination of classical PR controller and Model Based Predictive Voltage Control strategy for AC generation systems are presented. The performance of the system are analysed regarding tracking of reference and THD with satisfying transient results and THD lower than $1 \%$ in the injected current widely accomplishing with international standards.

Index Terms-Active and Reactive Power Control, Predictive Voltage Control, Matrix Converter, Grid Connected Generation Systems.
\end{abstract}

\section{INTRODUCTION}

The new energy paradigm knew as Distributed Generation Systems (DGS) is focused on the interaction between several energy sources, mainly using renewable energies, interacting in a synergistic manner based on small-scale, decentralised, local on-side generation [1]. Wind energy harvesting emerges as one of the most promising sources under DGS scheme [2]-[4]. The core of the wind DGS is the power electronic converter which role is becoming critical considering that many advanced functions can be realised through the control of this part of the system [5]. Direct Matrix Converter (DMC) consists of a semiconductor-based switches technology power converter that have many benefits because of the absence of large energy storage elements reducing the volume, enhancing the efficiency and increasing the lifetime, only requiring small filters to suppress the ripples generated by the switching actions [6].
In recent years, model based predictive control (MPC) has been successfully applied controlling various types of converters on several applications [7], [8], as for example torque and flux control [9], [10], current and power control [11], [12] and uninterrupted power supply (UPS) systems [13], [14].

MPC uses the model of the system in order to predict the future behaviour of it for every feasible input and chose the one that better fulfils some desired output defined by a cost function that is evaluated during every sampling time. The input that minimise the cost function is the one to be applied in the beginning of the next sampling time [15]. In the case of power converters, these are composed of semiconductors that operate in only two states: cutting and saturation. Therefore, there is always a finite number of possible combinations of switching states in any power converter. This feature greatly simplifies the application of the MPC, since, instead of having to waste time in a continuous optimisation algorithm, it is possible to perform the direct evaluation of all possible switching states and select the best combination to be used in accordance to the proposed control objectives. MPC has emerged as a plausible option for the controlled switching in power converters for applications in distributed generation systems [16]-[18]. The objective of these systems is to inject high quality controlled currents to the main distribution system and therefore controlling the active and reactive power.

The control objectives in the MPC are represented by a cost function, which evaluates the errors between the references and the actual values of the variables of interest. In addition, it is possible to add some additional control objectives such as temperature control and minimisation of commutation and conduction losses [19], common mode voltages reduction [20], among others. Also, non-linear operations, such as restrictions and limitations can be easily added, greatly increasing the 
flexibility and richness of the control strategy. It is possible to separate this operating principle into three steps (i) calculation of the predicted variables using the discrete model, (ii) evaluation of the cost function for each of the valid states of the converter, and (iii) selection and application of the optimal switching vector. These stages are present in all the MPC schemes, since it is possible to modify each independently to adjust the control scheme to any configuration.

In this paper a novel control scheme for $\mathrm{AC}$ generation systems under DG frame based on two cascaded control loops are proposed. The inner loop uses a predictive voltage control technique to regulate the voltage at the output capacitor of a DMC which is in turns connected to the grid at the Point of Common Coupling (PCC). The outer loop consist of a typical Proportional Resonant (PR) controller that generates a voltage reference signal depending on the desired injected current. Furthermore, a feed-forward voltage control strategy is added to the PR control signal in order to improve the transient response of the system.

\section{Proposed SCHEME FOR AC GENERATION SyStems UNDER DGS FRAME}

The general scheme for a grid connected AC generation system is shown in Fig. 1. This topology allows to inject controlled active and reactive power by means of controlling the voltage at the output capacitor $v_{o}$ and the injected current $i_{g}$. The Phase Locked Loop (PLL) block measures the phase of the grid voltage $\left(v_{g}\right)$ in order to generate a voltage synchronised with the same at the output of the converter. This process is carried out to interconnect both systems making feasible to inject power. Thus, a scheme with two control loops consisting of a combination of a predictive voltage control strategy and a current control loop that provides the voltage reference for the first one is proposed.

\section{InNer Predictive Voltage Control Loop}

When using cascade control loops, it is important to design a fast inner-control loop to achieve a correct behavior. Given that a known characteristic of MPC consist of fast transient response, it is particularly interesting to propose it as inner control loop strategy. Before to intent to control a system based on predictive control techniques, a precise model of the system is required. In this case it is needed to model first the direct matrix converter (DMC) and then the output filter. In the next section the DMC is modelled and analysed.

\section{A. Direct Matrix Converter. Basic Principles}

In order to introduce the basics regarding the DMC, the three-phase AC-AC conversion stage shown in Fig. 2 is considered.

The commutation function for a simple switch is defined as:

$$
S_{i j}=\left\{\begin{array}{ll}
0, & \text { switch } S_{i j} \text { off } \\
1, & \text { switch } S_{i j} \text { on }
\end{array},\right.
$$

where $i \in\{u, v, w\}$ indicates the correspond input and $j \in\{a, b, c\}$ the output. Since that the input never has to
TABLE I

VALID STATES FOR THE DMC.

\begin{tabular}{cccccccccc}
\hline & $S_{u a}$ & $S_{v a}$ & $S_{w a}$ & $S_{u b}$ & $S_{v b}$ & $S_{v c}$ & $S_{w a}$ & $S_{w b}$ & $S_{w c}$ \\
\hline 1 & 1 & 0 & 0 & 1 & 0 & 0 & 1 & 0 & 0 \\
2 & 0 & 1 & 0 & 1 & 0 & 0 & 1 & 0 & 0 \\
3 & 0 & 0 & 1 & 1 & 0 & 0 & 1 & 0 & 0 \\
4 & 1 & 0 & 0 & 0 & 1 & 0 & 1 & 0 & 0 \\
5 & 0 & 1 & 0 & 0 & 1 & 0 & 1 & 0 & 0 \\
6 & 0 & 0 & 1 & 0 & 1 & 0 & 1 & 0 & 0 \\
7 & 1 & 0 & 0 & 0 & 0 & 1 & 1 & 0 & 0 \\
8 & 0 & 1 & 0 & 0 & 0 & 1 & 1 & 0 & 0 \\
9 & 0 & 0 & 1 & 0 & 0 & 1 & 1 & 0 & 0 \\
10 & 1 & 0 & 0 & 1 & 0 & 0 & 0 & 1 & 0 \\
11 & 0 & 1 & 0 & 1 & 0 & 0 & 0 & 1 & 0 \\
12 & 0 & 0 & 1 & 1 & 0 & 0 & 0 & 1 & 0 \\
13 & 1 & 0 & 0 & 0 & 1 & 0 & 0 & 1 & 0 \\
14 & 0 & 1 & 0 & 0 & 1 & 0 & 0 & 1 & 0 \\
15 & 0 & 0 & 1 & 0 & 1 & 0 & 0 & 1 & 0 \\
16 & 1 & 0 & 0 & 0 & 0 & 1 & 0 & 1 & 0 \\
17 & 0 & 1 & 0 & 0 & 0 & 1 & 0 & 1 & 0 \\
18 & 0 & 0 & 1 & 0 & 0 & 1 & 0 & 1 & 0 \\
19 & 1 & 0 & 0 & 1 & 0 & 0 & 0 & 0 & 1 \\
20 & 0 & 1 & 0 & 1 & 0 & 0 & 0 & 0 & 1 \\
21 & 0 & 0 & 1 & 1 & 0 & 0 & 0 & 0 & 1 \\
22 & 1 & 0 & 0 & 0 & 1 & 0 & 0 & 0 & 1 \\
23 & 0 & 1 & 0 & 0 & 1 & 0 & 0 & 0 & 1 \\
24 & 0 & 0 & 1 & 0 & 1 & 0 & 0 & 0 & 1 \\
25 & 1 & 0 & 0 & 0 & 0 & 1 & 0 & 0 & 1 \\
26 & 0 & 1 & 0 & 0 & 0 & 1 & 0 & 0 & 1 \\
27 & 0 & 0 & 1 & 0 & 0 & 1 & 0 & 0 & 1 \\
\hline
\end{tabular}

be short-circuited and the current do not ever be abruptly interrupted, the follow constrains are defined:

$$
S_{u i}+S_{v i}+S_{w i}=1, \quad \forall i \in\{a, b, c\} .
$$

Under about mentioned constrains, three-phase DMC is able to generates 27 valid switching states among the feasible 512 $\left(2^{9}\right)$. The valid states for the DMC are depicted in Table I regarding equation (2).

If the power source and load are referenced to neutral point $(N)$, then it is possible to describe the relationship between inputs and outputs voltages and currents as follows:

$$
\begin{gathered}
{\left[\begin{array}{c}
v_{a}(t) \\
v_{b}(t) \\
v_{c}(t)
\end{array}\right]=\left[\begin{array}{lll}
S_{u a}(t) & S_{v a}(t) & S_{w a}(t) \\
S_{u b}(t) & S_{v b}(t) & S_{w b}(t) \\
S_{u c}(t) & S_{v c}(t) & S_{w c}(t)
\end{array}\right]\left[\begin{array}{c}
v_{u}(t) \\
v_{v}(t) \\
v_{w}(t)
\end{array}\right],} \\
{\left[\begin{array}{c}
i_{u}(t) \\
i_{v}(t) \\
i_{w}(t)
\end{array}\right]=\left[\begin{array}{lll}
S_{u a}(t) & S_{u b}(t) & S_{u c}(t) \\
S_{v a}(t) & S_{v b}(t) & S_{v c}(t) \\
S_{w a}(t) & S_{w b}(t) & S_{w c}(t)
\end{array}\right]\left[\begin{array}{c}
i_{o a}(t) \\
i_{o b}(t) \\
i_{o c}(t)
\end{array}\right] .}
\end{gathered}
$$

So as to calculate the effective voltages applied to every phase (i.e. from $a, b$ and $c$ to $n$ ), the common mode voltage $v_{n N}$ must to be subtracted from equation (3). It is possible to determine $v_{n N}$ easily applying "Kirchoff's Current Laws" as follows:

$$
v_{n N}=\frac{v_{a N}+v_{b N}+v_{c N}}{3}
$$

In this way, effective phase voltage is given by:

$$
\begin{aligned}
& v_{a n}=v_{a N}-v_{n N} \\
& v_{b n}=v_{b N}-v_{n N} \\
& v_{c n}=v_{c N}-v_{n N}
\end{aligned}
$$




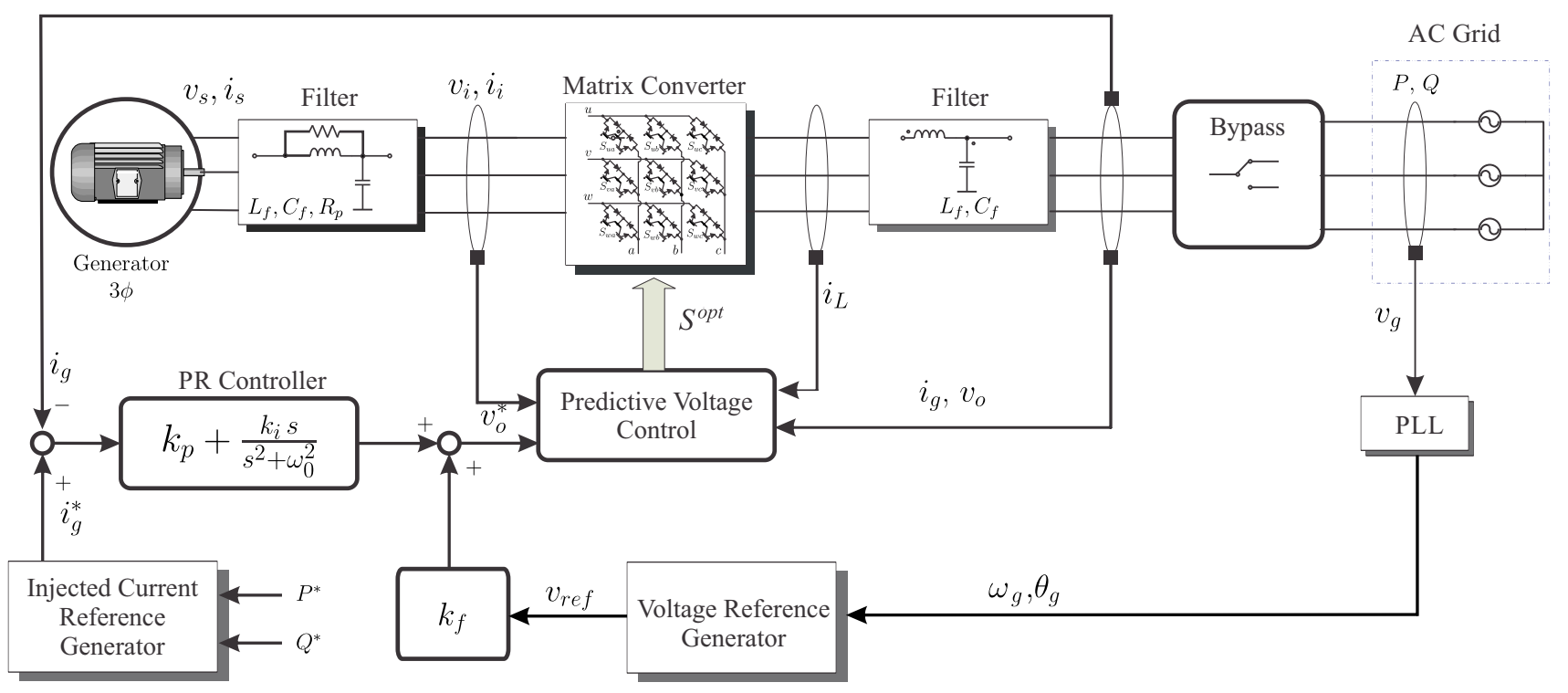

Fig. 1. Proposed Control Scheme

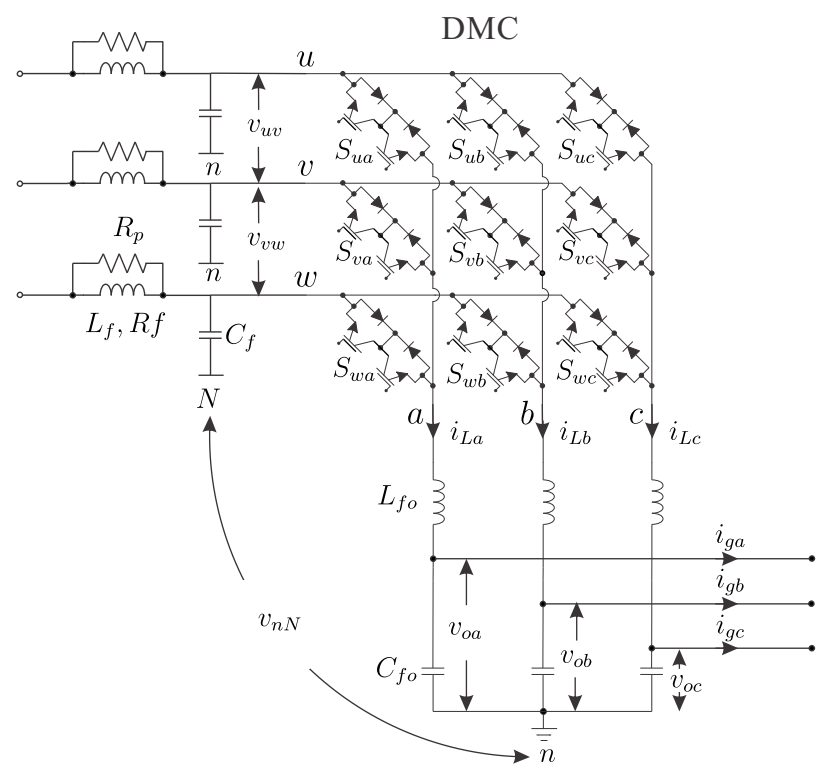

Fig. 2. Converter Topology.

\section{B. Output Filter Model}

In Fig. 2 it is possible to observe the $L C$ output filter on every phase of the DMC connected among the generation system and the PCC through a bypass switch. Every leg of the converter have an inductor $L_{f}$ with the corresponding leakage resistance $R_{f}$ and a capacitor $C_{f}$. Regarding the inductor current $i_{L}$ and the capacitor voltage $v_{c}$ as state variables and assuming all the parameters are the same in every leg, the system dynamic at the $(\alpha-\beta)$ reference plane is given by:

$$
L_{f} \frac{d i_{L \alpha \beta}}{d t}=v_{\alpha \beta}-v_{c \alpha \beta}-R_{f} i_{L \alpha \beta},
$$

where $v_{\alpha \beta}$ accrue to a valid vector shown on Table. I. In the other hand, the dynamic behaviour of the voltage through the capacitor of the filter is defined as follows:

$$
C_{f} \frac{d v_{c \alpha \beta}}{d t}=i_{L \alpha \beta}-i_{g \alpha \beta},
$$

In this way, the system's state-space representation is given by:

$$
\frac{d \mathbf{x}}{d t}=\mathbf{A} \mathbf{x}+\mathbf{B u}
$$

where

$$
\begin{aligned}
& \mathbf{x}=\left[\begin{array}{c}
i_{L \alpha \beta} \\
v_{c \alpha \beta}
\end{array}\right], \quad \mathbf{A}=\left[\begin{array}{cc}
-\frac{R_{f}}{L_{f}} & -\frac{1}{L_{f}} \\
\frac{1}{C_{f}} & 0
\end{array}\right], \\
& \mathbf{u}=\left[\begin{array}{c}
v_{\alpha \beta} \\
i_{g \alpha \beta}
\end{array}\right] \text { and } \mathbf{B}=\left[\begin{array}{cc}
\frac{1}{L_{f}} & 0 \\
0 & -\frac{1}{C_{f}}
\end{array}\right],
\end{aligned}
$$

The about mentioned equations define the continuous model of the $L C$ filter considering the output voltage of the DMC $v_{\alpha \beta}$ and the output current injected to the grid $i_{g \alpha \beta}$ as state variables.

\section{Discrete Time Model for the LC Filter}

The discrete model of the system is given by:

$$
\mathbf{x}(k+1)=\mathbf{A}_{d} \mathbf{x}(k)+\mathbf{B}_{d} \mathbf{u}(k),
$$

being $\mathbf{A}_{d}=e^{\mathbf{A} T_{s}}, \mathbf{B}_{d}=\int_{0}^{T_{s}} e^{\mathbf{A}\left(T_{s}-\tau\right)} \mathbf{B} d \tau, \mathbf{A}$ and $\mathbf{B}$ are given by eq. (10) and $T_{s}$ is the sampling time. Thus, by using a discrete model that describes the system it is possible to predict the states of $v_{o}$ e $i_{L}$ as follows:

$i_{L}(k+1)=a_{11} i_{L}(k)+a_{12} v_{o}(k)+b_{11} v(k)+b_{12} i_{g}(k)$, 


$$
v_{o}(k+1)=a_{21} i_{L}(k)+a_{22} v_{o}(k)+b_{21} v(k)+b_{22} i_{g}(k),
$$

being

$$
\mathbf{A}_{d}=\left[\begin{array}{ll}
a_{11} & a_{12} \\
a_{21} & a_{22}
\end{array}\right], \mathbf{B}_{d}=\left[\begin{array}{ll}
b_{11} & b_{12} \\
b_{21} & b_{22}
\end{array}\right]
$$

where $k$ denotes the present sampling time and $k+1$ indicates the beginning of the next sampling time. As from the preceding equations it is possible to predict the values of the current at the inductor and the output voltage in order to use them in the implementation of the predictive control.

Once the converter model is defined, the next step consist of design the control scheme.

\section{Predictive Voltage Control}

The basic operating principle of the algorithm is the following: first, at the beginning of the sampling instant, new measurements of $v_{o}, i_{L}$ and $i_{g}$ are obtained. These measurements define the starter point from which the algorithm predicts the future trajectory of the state space variables by considering (12) and (13), for each feasible voltage vector. Every predicted value is evaluated with a pre-designed cost function $(\mathrm{CF})$, and the vector with the lowest $\mathrm{CF}$ is applied to the DMC switches. The presented technique is based on the proposed control in [21], [22]. The selected cost function is the following:

$$
g=\left(v_{o \alpha}^{*}-v_{o \alpha}\right)^{2}+\left(v_{o \beta}^{*}-v_{o \beta}\right)^{2}+\lambda_{d} g_{d e r},
$$

being $v_{o \alpha}^{*}$ and $v_{o \beta}^{*}$ the desired voltages on the $\alpha-\beta$ plane and defining:

$g_{d e r}=\left(C_{f} \omega_{r e f} v_{o \beta}^{*}-i_{L \alpha}+i_{g \alpha}\right)^{2}+\left(C_{f} \omega_{r e f} v_{o \alpha}^{*}-i_{L \beta}+i_{g \beta}\right)^{2}$.

The term $g_{d e r}$ is introduced with the purpose of correcting the incapacity of the classic predictive control of tracking the capacitor voltage derivative resulting in a high total harmonic distortion (THD), creating an ideal regulator which controls the voltage capacitor and its derivative effectively. The effect of the derivative term is controlled with a weighting factor $\lambda_{d}$ that was chosen considering [21]. This strategy is based on the evaluation, at every sampling instant, of the cost function $g$ for all the valid vectors and to apply the vector which minimises the $\mathrm{CF}$ in the next sampling instant achieving a desired voltage tracking.

\section{OUTER CURRENT CONTROL LOOP FOR REFERENCE VOLTAGE GENERATION}

As mentioned above, the proposed scheme is based on the implementation of two control loops, an internal loop corresponding to the predictive voltage control and an external loop that generates the voltage reference to inject a controlled current into the grid. In Fig. 1 the external control loop is shown where the difference between the injected current $i_{g}$ and the desired current $i_{g}^{*}$ is calculated to be applied as the input of a PR controller [23] which output is added to a feedforward control signal $v_{\text {ref }}$ which is used at system startup to synchronise the output voltage of the conversion stage $v_{o}$ with the grid voltage $v_{g}$ so as to be connected through a bypass. This generated reference voltage is the input to the voltage predictive control block to calculate the optimum vector to be applied. The voltage $v_{r e f}$ is generated from the measurement of the phase of the grid $\theta$ obtained from the PLL and the amplitude of the signal of the grid. The value of $i_{g}^{*}$ is determined from the current amplitude and phase according to the desired active and reactive power.

\section{A. Current References generation based on desired $P$ and $Q$}

Active and reactive power references in currents terms are defined by the following equations [24]:

$$
i_{g \alpha}^{*}=\frac{2}{3} \frac{v_{g \alpha}}{v_{g \alpha}^{2}+v_{g \beta}^{2}} P^{*}+\frac{2}{3} \frac{v_{g \beta}}{v_{g \alpha}^{2}+v_{g \beta}^{2}} Q^{*}
$$

and

$$
i_{g \beta}^{*}=\frac{2}{3} \frac{v_{g \beta}}{v_{g \alpha}^{2}+v_{g \beta}^{2}} P^{*}-\frac{2}{3} \frac{v_{g \alpha}}{v_{g \alpha}^{2}+v_{g \beta}^{2}} Q^{*}
$$

where $P^{*}$ and $Q^{*}$ denote the active and reactive power references, respectively, while $v_{g s \alpha}$ and $v_{g \beta}$ are the grid voltages in stationary reference frame $(\alpha-\beta)$.

\section{GRID CONNECTION PROCEDURE}

In order to perform the grid connection, the steps described below must to be followed.

1) The predictive voltage control is used to generate an output voltage $\left(v_{o}\right)$ synchronised with the grid voltage $\left(v_{g}\right)$, that is, the voltage of the capacitor is synchronised with the grid in each phase. This part of the procedure is shown in Fig.3.

2) Next, once the voltages are equal, the bypass is used to connect the systems setting the power reference $P$ and $Q$ to zero, that is, choosing the desired injected current $i_{g} *$ to zero.

3) Finally, the feed-forward signal can be set to zero and all the reference voltage comes from the PR controller, then it is possible to select the desired injected active and reactive power that generate the current reference for the PR controller.

Based on the above described procedure, it is possible to evaluate the proposal based on perform some simulations using MATLAB/Simulink environment.

\section{Simulation RESUlts AND ANALYSis}

In order to validate the proposal, a simulation using the parameters depicted on Table II is performed. As was mentioned previously, Fig. 3 shows the synchronisation process, it is possible to appreciate that it takes around 0.18 seconds to synchronise the output voltage of the generation stage $v_{o}$ with the grid voltage $v_{g}$ in each phase. Once the synchronisation is achieved, the output filter is connected to the grid through a bypass switch, holding the desired power reference to zero. So as to show the desired power tracking and to analyse the 

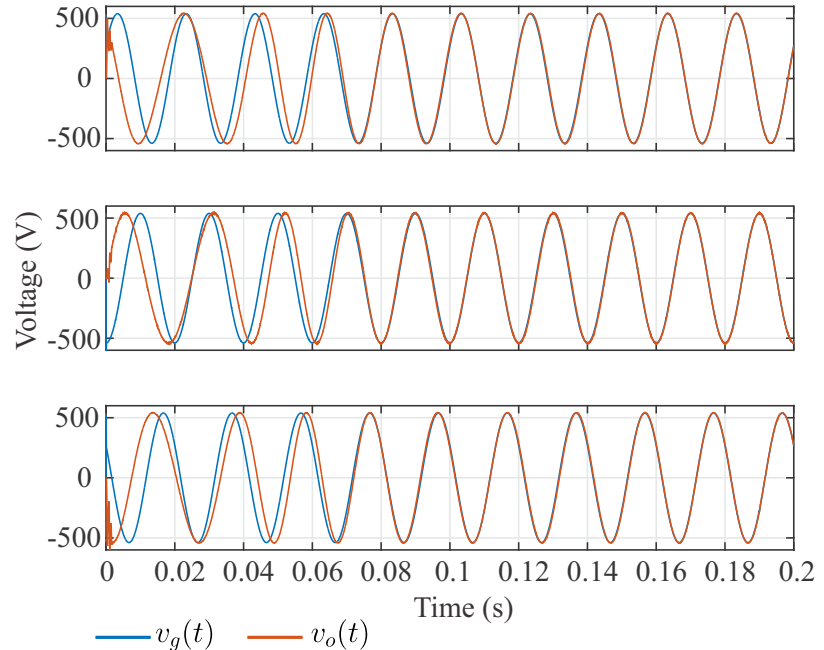

Fig. 3. Output voltage of conversion system during synchronisation process.

TABLE II

IMPLEMENTED PARAMETERS ON THE SIMULATION ENVIRONMENT.

\begin{tabular}{lccc}
\hline & \multicolumn{3}{c}{ Description } \\
\cline { 2 - 4 } Parameter & Symbol & Value & Unit \\
\hline \hline Grid Voltage & $v_{g}$ & 311 & $V_{p}$ \\
Grid frequency & $f_{g}$ & 50 & $\mathrm{~Hz}$ \\
Generator Voltage & $v_{s}$ & 540 & $V_{p}$ \\
Generator frequency & $f_{s}$ & 50 & $\mathrm{~Hz}$ \\
Input Filter Resistance & $R_{p}$ & 100 & $\Omega$ \\
Leakage Inductor Resistance & $R_{f}$ & 10 & $\mathrm{~m} \Omega$ \\
Input Filter Inductance & $L_{f}$ & 2.4 & $\mathrm{mH}$ \\
Input Filter Capacitance & $C_{f}$ & 24 & $\mu \mathrm{F}$ \\
Sampling Time & $T_{s}$ & 25 & $\mu s$ \\
Sampling frequency & $f_{s}$ & 40 & $\mathrm{kHz}$ \\
Derivative weighting & $\lambda_{d}$ & 0.2 & \\
PR proportional constant & $k_{p}$ & 10 & \\
PR integral constant & $k_{i}$ & 1500 & \\
Output Filter Inductance & $L_{f o}$ & 2.4 & $\mathrm{mH}$ \\
Output Filter Capacitance & $C_{f o}$ & 24 & $\mu \mathrm{F}$ \\
\hline
\end{tabular}

transient response, in Fig. 4 the active and reactive power are shown. It is possible to notice the correct tracking of active power by the response to several steps beginning with a reference of 2000 watts and increasing the power in steps of 2000 watts, holding the reactive power to zero. The transient response is about 1 millisecond that is quick enough concerning the application. Related to reactive power injection, Fig. 5 shows a step response beginning with -1000 VA and increasing up to 1000 VA holding the active power on zero. Fig. 6 and Fig.7 depict the spectral response of the injected current of the system where the desired active power was set to $2.5 \mathrm{~kW}$ first and then to $5 \mathrm{~kW}$ resulting currents of about 5 and 10 amps. In the first case the THD was $1.05 \%, 1.02 \%$ and $1.03 \%$ for each phase, and in the second $0.55 \%, 0.52 \%$ and $0.51 \%$ fulfilling the required level for this magnitude in distributed generation systems which validate the performance of the proposal.
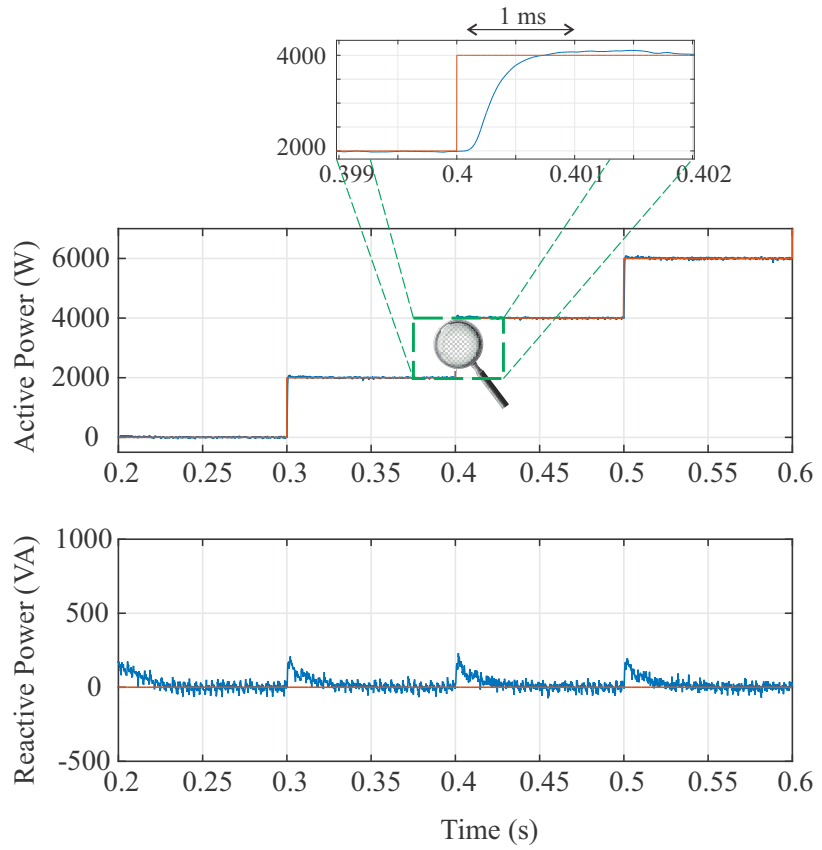

Fig. 4. Power tracking performance of the system for Active Power injection with zero reactive power.
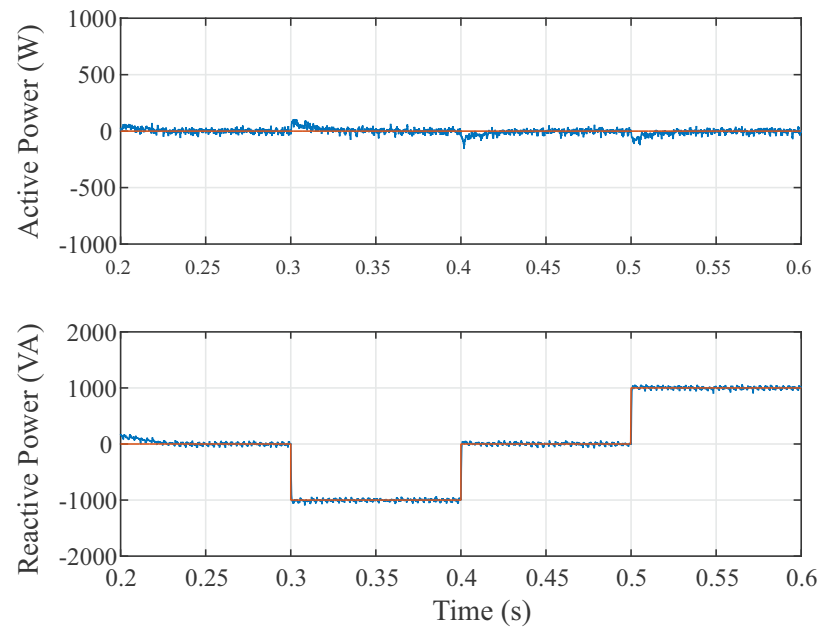

Fig. 5. Power tracking performance of the system for Reactive Power injection with zero active power.
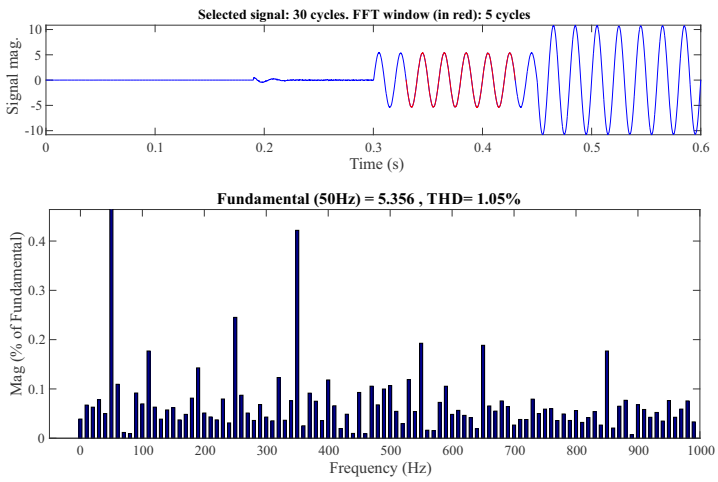

Fig. 6. Spectral performance of the system for $2500 \mathrm{~W}$. 

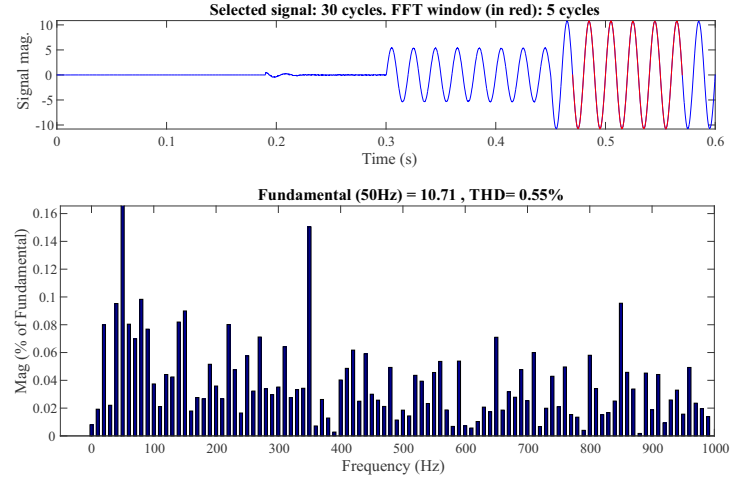

Fig. 7. Spectral performance of the system for $5000 \mathrm{~W}$.

\section{CONCLUSION}

It can be seen by the performed simulations that the proposal shows a correct behaviour, with acceptable transient response and good THD regarding the international standards for DGS. It has been proven that it is feasible to implement a control technique that involves two cascade control loops, one internal based on Predictive Voltage control that have as main characteristic a fast response, and an outer classic PR control loop, that compare the injected current with the desired current generates from the desired active and reactive power.

The proposed topology reduce the THD using a weighted derivative tracking term in the cost function of the predictive controller allowing to improve harmonic response in contravention of worsening the reference tracking. This derivative term makes possible to implement a 1-horizon of prediction technique instead a 2-horizon one for second order systems with good response.

Finally it is possible to affirm that the proposal is viable for its implementation on DGS systems controlling the injected active and reactive power with good signals quality, both in terms of transient response and harmonic content.

\section{ACKNOWLEDGMENT}

The authors express their gratitude to Consejo Nacional de Ciencia y Tecnología de Paraguay (CONACYT), for the support and financing through Project PINV15-0584, to CONICYT of Chile through the FONDECYT Regular Project 1160690, Project MEC 80150056 and CONICYTPFCHA/Doctorado Nacional/2019-21192003.

\section{REFERENCES}

[1] V. Smil, "Distributed generation and megacities: Are renewables the answer?" IEEE Power and Energy Magazine, vol. 17, no. 2, pp. 37-41, March 2019.

[2] F. Blaabjerg and K. Ma, "Wind energy systems," Proceedings of the IEEE, vol. PP, no. 99, pp. 1-16, 2017.

[3] V. Yaramasu, B. Wu, P. C. Sen, S. Kouro, and M. Narimani, "Highpower wind energy conversion systems: State-of-the-art and emerging technologies," Proceedings of the IEEE, vol. 103, no. 5, pp. 740-788, May 2015.

[4] S. Toledo, M. Rivera, and J. L. Elizondo, "Overview of wind energy conversion systems development, technologies and power electronics research trends," in 2016 IEEE International Conference on Automatica (ICA-ACCA), Oct 2016, pp. 1-6.
[5] F. Blaabjerg, Y. Yang, D. Yang, and X. Wang, "Distributed powergeneration systems and protection," Proceedings of the IEEE, vol. 105, no. 7, pp. 1311-1331, July 2017.

[6] J. Zhang, L. Li, and D. G. Dorrell, "Control and applications of direct matrix converters: A review," Chinese Journal of Electrical Engineering, vol. 4, no. 2, pp. 18-27, June 2018.

[7] V. P. K. Kunisetti, R. E. K. Meesala, and V. K. Thippiripati, "Improvised predictive torque control strategy for an open end winding induction motor drive fed with four-level inversion using normalised weighted sum model," IET Power Electronics, vol. 11, no. 5, pp. 808-816, 2018.

[8] J. Falck, G. Buticchi, and M. Liserre, "Thermal stress based model predictive control of electric drives," IEEE Transactions on Industry Applications, vol. 54, no. 2, pp. 1513-1522, March 2018.

[9] K. V. P. Kumar and T. V. Kumar, "Predictive torque control of open-end winding induction motor drive fed with multilevel inversion using two two-level inverters," IET Electric Power Applications, vol. 12, no. 1, pp. 54-62, 2018.

[10] K. M. R. Eswar, K. V. P. Kumar, and T. V. Kumar, "Modified predictive torque and flux control for open end winding induction motor drive based on ranking method," IET Electric Power Applications, vol. 12, no. 4, pp. 463-473, 2018.

[11] P. Wheeler, M. Rivera, and S. Toledo, "An indirect model predictive current control for a direct matrix converter with instantaneous reactive power minimization," in 2017 IEEE Southern Power Electronics Conference (SPEC), Dec 2017, pp. 1-6.

[12] F. Zhang, Y. Du, W. Liu, and P. Li, "Model predictive power control for cooperative vehicle safety systems," IEEE Access, vol. 6, pp. 47974810, 2018.

[13] M. Novak, U. M. Nyman, T. Dragicevic, and F. Blaabjerg, "Analytical design and performance validation of finite set mpc regulated power converters," IEEE Transactions on Industrial Electronics, pp. 1-1, 2018.

[14] S. Toledo, E. Maqueda, M. Rivera, T. Dragicevic, and R. Gregor, "Predictive voltage control techniques for ac ups applications," in 2018 IEEE International Conference on Automation/XXIII Congress of the Chilean Association of Automatic Control (ICA-ACCA), Oct 2018, pp. 1-6.

[15] T. Geyer, Model Predictive Control of High Power Converters and Industrial Drives. Wiley, 2016. [Online]. Available: https://books.google.com.py/books?id=ovVmCgAAQBAJ

[16] S. Toledo, M. Rivera, R. Gregor, J. Rodas, and L. Comparatore, "Predictive current control with reactive power minimization in six-phase wind energy generator using multi-modular direct matrix converter," in 2016 IEEE ANDESCON, Oct 2016, pp. 1-4.

[17] M. Rivera, P. Wheeler, A. Olloqui, and D. A. Khaburi, "A review of predictive control techniques for matrix converters - Part I," in 2016 7th Power Electronics and Drive Systems Technologies Conference (PEDSTC), Feb 2016, pp. 582-588.

[18] _ - "A review of predictive control techniques for matrix converter Part II," in 2016 7th Power Electronics and Drive Systems Technologies Conference (PEDSTC), Feb 2016, pp. 589-595.

[19] J. Falck, M. Andresen, and M. Liserre, "Thermal-based finite control set model predictive control for igbt power electronic converters," in 2016 IEEE Energy Conversion Congress and Exposition (ECCE), Sept 2016 , pp. 1-7.

[20] H. Gao, B. Wu, D. . Xu, M. Pande, and R. P. Aguilera, "Common-modevoltage-reduced model-predictive control scheme for current-sourceconverter-fed induction motor drives," IEEE Transactions on Power Electronics, vol. 32, no. 6, pp. 4891-4904, Jun 2017.

[21] T. Dragičević, "Model predictive control of power converters for robust and fast operation of ac microgrids," IEEE Transactions on Power Electronics, vol. 33, no. 7, pp. 6304-6317, 2018.

[22] T. Dragicevic, C. Zheng, J. Rodriguez, and F. Blaabjerg, "Robust quasipredictive control of lcl-filtered grid converters," IEEE Trans. Power Electron., pp. 1-1, 2019.

[23] S. A. Richter and R. W. De Doncker, "Digital proportional-resonant (pr) control with anti-windup applied to a voltage-source inverter," in Proceedings of the 2011 14th European Conference on Power Electronics and Applications, Aug 2011, pp. 1-10.

[24] Y. Bak, E. Lee, and K.-B. Lee, "Indirect matrix converter for hybrid electric vehicle application with three-phase and single-phase outputs," Energies, vol. 8, no. 5, pp. 3849-3866, 2015. 